\title{
Improved Rotor Position Estimation by Signal Injection in Brushless AC Motors, Accounting for Cross-Coupling Magnetic Saturation
}

\author{
Y. Li, Z. Q. Zhu, D. Howe, C. M. Bingham, and D. Stone \\ Department of Electronic and Electrical Engineering, University of Sheffield, Mappin Street, Sheffield S1 3JD, UK
}

\begin{abstract}
The paper presents an improved signal injectionbased sensorless control method for permanent magnet brushless AC (BLAC) motors, accounting for the influence of cross-coupling magnetic saturation between the $d$ - and $q$ axes. The $d$ - and $q$-axis incremental self-inductances, the incremental mutual-inductance between the $d$-axis and $q$ axis, and the cross-coupling factor are determined by finite element analysis. A method is also proposed for measuring the cross-coupling factor which can be used directly in the sensorless control scheme. Both measurements and predictions show that a significant improvement in the accuracy of the rotor position estimation can be achieved under both dynamic and steady-state operation, compared with that which is obtained with the conventional signal injection method.
\end{abstract}

Keywords- brushless AC motor, cross-coupling effect, sensorless, signal injection.

\section{INTRODUCTION}

Accurate rotor position information is an essential requirement for permanent magnet $(\mathrm{PM})$ brushless $\mathrm{AC}$ (BLAC) drives. Thus, either an encoder or a resolver is usually employed. However, this increases the cost and complexity, and may compromise the reliability. Hence, there has been a significant development effort on sensorless techniques, which estimate the rotor position indirectly from the phase voltages and currents.

Various back-emf-based rotor position estimation methods have been developed for PM BLAC motors [13], which all estimate the rotor position from the governing voltage equation, their difference being in the way that the rotor position and speed estimation are deduced. However, they require accurate stator winding inductances and resistances, may be problematic at low speed and cannot be used for starting.

Hence, the most popular sensorless control method for starting and low speed operation is based on injecting a high frequency voltage signal into the phase windings and measuring the resultant high frequency current. Such a method was originally developed for induction motors, and was subsequently extended to PM BLAC motors with saliency [4-6]. The identification of the initial rotor polarity, which was not reported in [4-6], was achieved in [7] [8] by comparing sine and cosine terms of the 2nd harmonic component in the d-axis current. In all the foregoing papers, the signal injection technique was applied to BLAC motors, which have geometric rotor saliency. In [9], it was extended to a BLAC motor with a surface-mounted PM rotor by utilizing the saliency which resulted from magnetic saturation.

However, it was found experimentally [5] that the error in the estimated rotor position increased with the load current, although the problem was not specifically addressed. More recently, it was shown in [10] [11] that the rotor position estimation error was caused by $d q$ axis cross-coupling, i.e. $L_{d q h} \neq 0$, and was dependent on the machine design, although no measures were taken to reduce the error. It is well-known that the mutual inductance between the d- and q-axes $\left(L_{d q h}\right)$ of a BLAC motor results from cross-coupling due to magnetic saturation, as shown in [12] by both measurement and finite element analysis. However, for simplicity, the influence of cross-coupling magnetic saturation is usually neglected in the electromagnetic modeling [13] [14], vector control [15] [16], and sensorless position control [5-9] of BLAC motors.

This paper improves the accuracy of the rotor position estimation by accounting for the influence of crosscoupling magnetic saturation in the signal injection based sensorless method. Section II presents the underlying theory and analyzes the rotor position estimation error which results when the influence of cross-coupling is neglected. Section III proposes a simple way of accounting for the cross-coupling based on data which can be obtained either by finite element analysis or from measurements. Finally, predicted and measured results are compared in section IV to validate the proposed improved signal injection sensorless control method.

\section{ANALYSIS OF Rotor POSITION ESTIMATION ERror CAUSED BY CROSS-COUPLING}

When cross-coupling between the $d$ - and $q$-axes is considered, the voltage equations of a BLAC motor, in the rotor $d q$-axis reference frame, are given by [12]:

$$
\left[\begin{array}{l}
v_{d} \\
v_{q}
\end{array}\right]=\left[\begin{array}{cc}
R_{s}+L_{d h} p & -\omega_{r} L_{q}+L_{d q h} p \\
\omega_{r} L_{d}+L_{q d h} p & R_{s}+L_{q h} p
\end{array}\right]\left[\begin{array}{c}
i_{d} \\
i_{q}
\end{array}\right]+\left[\begin{array}{c}
0 \\
\omega_{r} \psi_{m}
\end{array}\right]
$$


where $R_{s}$ is the stator winding phase resistance and $\psi_{m}$ is the flux-linkage per phase due to the permanent magnets, $\omega_{r}$ is the angular rotational speed, $p=d / d t . v_{d}, v_{q}$ and $i_{d}, i_{q}$ are the $d$ - and $q$-axis voltages and currents, $L_{d}$ and $L_{q}$ are the apparent $d-q$ axis self-inductances, respectively, and $L_{d h}, L_{q h}, L_{d q h}$ and $L_{q d h}$ are the $d$ - and $q$-axis incremental self- and mutual-inductances, defined by:

$$
\left\{\begin{array}{l}
L_{d h}=\left[\psi_{d}\left(i_{d}+\Delta i_{d}, i_{q}, \Phi_{m}\right)-\psi_{d}\left(i_{d}, i_{q}, \Phi_{m}\right)\right] / \Delta i_{d} \\
L_{q h}=\left[\psi_{q}\left(i_{d}, i_{q}+\Delta i_{q}, \Phi_{m}\right)-\psi_{q}\left(i_{d}, i_{q}, \Phi_{m}\right)\right] / \Delta i_{q} \\
L_{d q h}=\left[\psi_{d}\left(i_{d}, i_{q}+\Delta i_{q}, \Phi_{m}\right)-\psi_{d}\left(i_{d}, i_{q}, \Phi_{m}\right)\right] / \Delta i_{q} \\
L_{q d h}=\left[\psi_{q}\left(i_{d}+\Delta i_{d}, i_{q}, \Phi_{m}\right)-\psi_{q}\left(i_{d}, i_{q}, \Phi_{m}\right)\right] / \Delta i_{d}
\end{array}\right.
$$

where $\Phi_{m}$ is the permanent magnet flux.

Due to magnetic saturation, $L_{d h}, L_{q h}, L_{d q h}$ and $L_{q d h}$ vary with both $i_{d}$ and $i_{q}$. By way of example, Fig. 1 shows the finite element calculated incremental winding inductances for the interior-magnet brushless AC motor whose parameters are given in Table I. As can be seen, $L_{d h}$ and $L_{q h}$ reduce as $i_{d}$ and $i_{q}$ are increased.

TABLE I. PARAMETERS OF BLAC MOTOR

\begin{tabular}{|l|l|}
\hline Rated voltage (peak) & $158 \mathrm{~V}$ \\
\hline Rated current (peak) & $4.0 \mathrm{~A}$ \\
\hline Rated power & $0.6 \mathrm{~kW}$ \\
\hline Rated speed & $1000 \mathrm{rpm}$ \\
\hline Rated torque & $4.0 \mathrm{Nm}$ \\
\hline Pole number & 6 \\
\hline Stator resistance $\left(R_{s}\right)$ & $6.0 \Omega$ \\
\hline
\end{tabular}

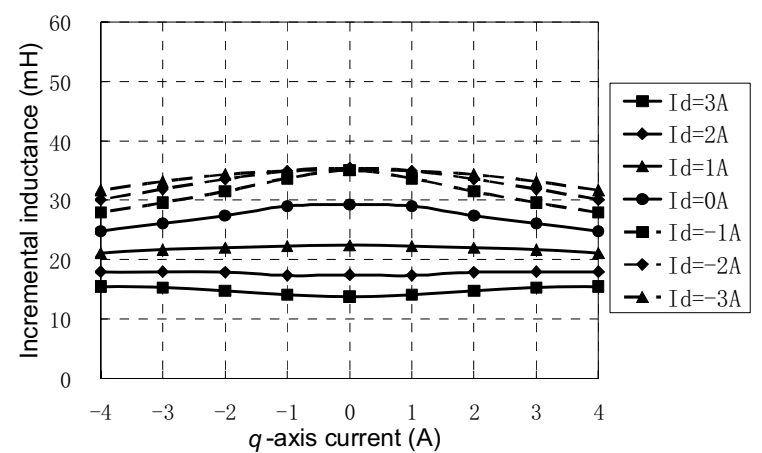

(a) $d$-axis incremental self-inductance, $L_{d h}$

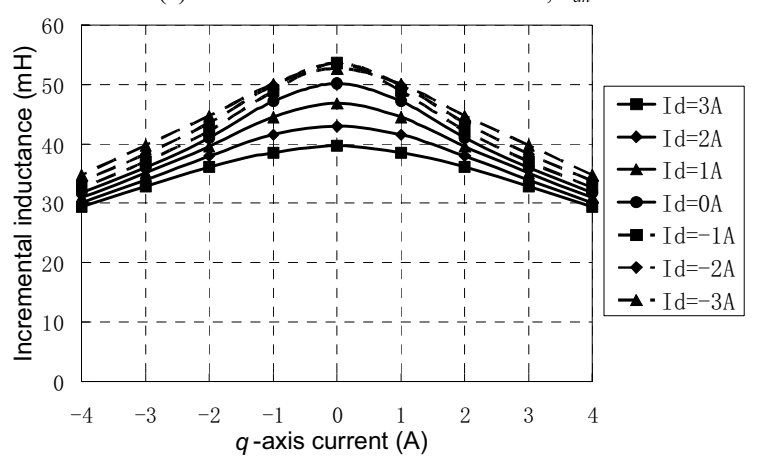

(b) $q$-axis incremental self-inductance, $L_{q h}$

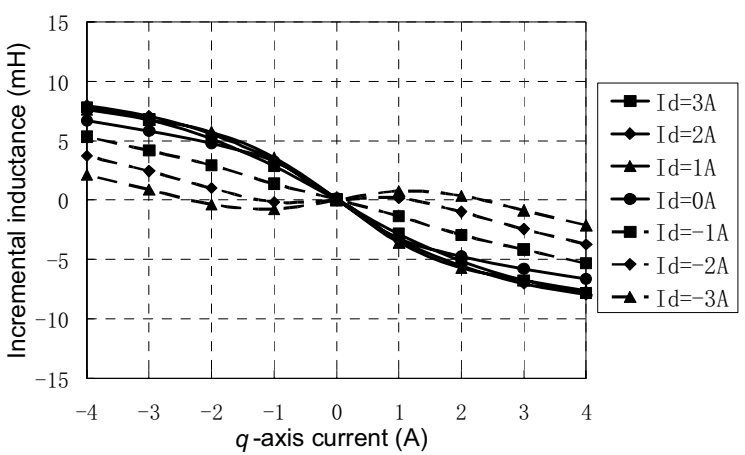

(c) $d q$-axis incremental mutual-inductances, $L_{d q h}$ and $L_{q d h}$

Fig. 1. Finite element predicted incremental self- and mutualinductances.

When only the high frequency signal injection components are considered, (1) can be approximated by:

$\left[\begin{array}{c}v_{d h} \\ v_{q h}\end{array}\right]=\left[\begin{array}{cc}L_{d h} & L_{d q h} \\ L_{d q h} & L_{q h}\end{array}\right] p\left[\begin{array}{c}i_{d h} \\ i_{q h}\end{array}\right]$

(3) can be transformed from the rotor position reference frame $\left(\theta_{r}\right)$ to the estimated rotor position reference frame $\left(\theta_{r}{ }^{e}\right)$ by the transformation matrix, $T(\Delta \theta)$, viz.:

$$
T(\Delta \theta)=\left[\begin{array}{cc}
\cos (\Delta \theta) & \sin (\Delta \theta) \\
-\sin (\Delta \theta) & \cos (\Delta \theta)
\end{array}\right]
$$

where $\Delta \theta$ is the error in the estimated rotor position, i.e. $\Delta \theta=\theta_{r}{ }^{e}-\theta_{r}$ is the difference between the estimated rotor position and the actual rotor position. Hence,

$$
\begin{aligned}
& {\left[\begin{array}{c}
v_{d h}^{e} \\
v_{q h}^{e}
\end{array}\right]=T(\Delta \theta)\left[\begin{array}{l}
v_{d h} \\
v_{q h}
\end{array}\right]=T(\Delta \theta)\left[\begin{array}{cc}
L_{d h} & L_{d q h} \\
L_{d q h} & L_{q h}
\end{array}\right] T^{-1}(\Delta \theta) \cdot p\left[\begin{array}{c}
i_{d h}^{e} \\
i_{q h}^{e}
\end{array}\right]} \\
& =\left[\begin{array}{cc}
L_{a v g}-\hat{L}_{d i f} \cos \left(2 \Delta \theta+\theta_{m}\right) & \widehat{L}_{d i f} \sin \left(2 \Delta \theta+\theta_{m}\right) \\
\hat{L}_{d i f} \sin \left(2 \Delta \theta+\theta_{m}\right) & L_{a v g}+\widehat{L}_{d i f} \cos \left(2 \Delta \theta+\theta_{m}\right)
\end{array}\right] p\left[\begin{array}{c}
i_{d h}^{e} \\
i_{q h}^{e}
\end{array}\right]
\end{aligned}
$$

where

$$
\begin{aligned}
& \left\{\begin{array}{l}
L_{a v g}=\left(L_{q h}+L_{d h}\right) / 2 \\
L_{d i f}=\left(L_{q h}-L_{d h}\right) / 2
\end{array}\right. \\
& \left\{\begin{array}{l}
\theta_{m}=\arctan \left(L_{d q h} / L_{d i f}\right)=\arctan \left[2 L_{d q h} /\left(L_{q h}-L_{d h}\right)\right] \\
\widehat{L}_{d i f}=\sqrt{L_{d i f}^{2}+L_{d q h}^{2}}
\end{array}\right.
\end{aligned}
$$

Since the high frequency voltage signal, $v_{s i g}=V_{i n j} \sin \left(2 \pi f_{H F} t\right)$, is applied to the $d$-axis, (5) becomes:

$$
\left[\begin{array}{c}
v_{\text {sig }} \\
0
\end{array}\right]=\left[\begin{array}{cc}
L_{\text {avg }}-\widehat{L}_{\text {dif }} \cos \left(2 \Delta \theta+\theta_{m}\right) & \widehat{L}_{\text {dif }} \sin \left(2 \Delta \theta+\theta_{m}\right) \\
\widehat{L}_{\text {dif }} \sin \left(2 \Delta \theta+\theta_{m}\right) & L_{\text {avg }}+\widehat{L}_{\text {dif }} \cos \left(2 \Delta \theta+\theta_{m}\right)
\end{array}\right] p\left[\begin{array}{c}
i_{d h}^{e} \\
i_{q h}^{e}
\end{array}\right]
$$


The high frequency $d$ - and $q$-axis currents in the estimated rotor position reference frame are obtained as:

$$
\left\{\begin{array}{l}
i_{d h}^{e}=\frac{v_{\text {sig }}}{p\left(\hat{L}_{\text {avg }}^{2}-\widehat{L}_{d i f}^{2}\right)}\left[L_{\text {avg }}+\widehat{L}_{\text {dif }} \cos \left(2 \Delta \theta+\theta_{m}\right)\right] \\
i_{q h}^{e}=-\frac{v_{\text {sig }}}{p\left(L_{\text {avg }}^{2}-\widehat{L}_{d i f}^{2}\right)} \widehat{L}_{d i f} \sin \left(2 \Delta \theta+\theta_{m}\right)
\end{array}\right.
$$

In the conventional signal injection based sensorless method, cross-coupling between the $d$ - and $q$-axes is neglected, and the high frequency component in the $q$-axis current is forced to be zero [9], i.e.:

$$
i_{q h}^{e}=-\frac{v_{\text {sig }}}{p\left(L_{\text {avg }}^{2}-\widehat{L}_{\text {dif }}^{2}\right)} \widehat{L}_{\text {dif }} \sin \left(2 \Delta \theta+\theta_{m}\right)=0
$$

In this case, an error exists in the estimated rotor position as a result of the incremental mutual inductance between the $d$ - and $q$-axes, $L_{d q h}$. The error is given by:

$$
\Delta \theta=\theta_{r}^{e}-\theta_{r}=-\theta_{m} / 2 \approx \frac{1}{2} \arctan \left(\frac{2 L_{d q h}}{L_{d h}-L_{q h}}\right)
$$

where $\theta_{r}^{e}$ and $\theta_{r}$ are the estimated and actual rotor positions, respectively.

Clearly, the rotor position error will be zero only when $L_{d q h}=0$, while the stronger the cross-coupling between the $d$ - and $q$-axes, the larger will be the error, as will be shown later.

\section{IMPROVED Signal INJECTION SENSORLESS METHOD}

In [17], the error in the estimated rotor position due to the neglect of the incremental mutual inductance between the $d$ - and $q$-axes, $L_{d q h}$, was analyzed by finite element analysis and experimentally, and a method was proposed to directly compensate for the error by employing (11) based on either the finite element predicted incremental inductances, $L_{d h}, L_{q h}, L_{d q h}$, which are shown in Fig.1, or using pre-measured errors. However, this improved method was still essentially based on the conventional sensorless method which forces the high frequency component in the $q$-axis current to be zero, together with the error compensation.

In this section, an alternative method of improving the signal injection based sensorless method is proposed to eliminate the potentially large error in the estimated rotor position caused by the influence of $d$ - and $q$-axis crosscoupling, i.e. $L_{d q h} \neq 0$. Rather than forcing the high frequency component in the $q$-axis current to be zero, as in the conventional sensorless method, an optimal relationship between the high frequency components of the $d$ - and $q$-axis currents is established from the analysis presented in section II.
When the rotor position estimation error $\Delta \theta$ is sufficiently small, (9) can be approximated by:

$$
\begin{aligned}
& i_{d h}^{e} \approx \frac{v_{s i g}}{p\left(L_{a v g}^{2}-\widehat{L}_{d i f}^{2}\right)}\left(L_{q h}-2 L_{d q h} \cdot \Delta \theta\right) \\
& i_{q h}^{e} \approx \frac{v_{s i g}}{p\left(L_{\text {avg }}^{2}-\widehat{L}_{d i f}^{2}\right)}\left(-L_{d q h}-2 L_{d i f} \cdot \Delta \theta\right)
\end{aligned}
$$

Both sides of (12a) are multiplied by $L_{d q h} / L_{q h}$, and added to (12b), to give:

$$
i_{q h}^{e}+\lambda i_{d h}^{e}=\frac{v_{s i g}}{p\left(L_{a v g}^{2}-\widehat{L}_{d i f}^{2}\right)}\left(-2 L_{d i f}-2 \lambda L_{d q h}\right) \cdot \Delta \theta
$$

where $\lambda=L_{d q h} / L_{q h}$ is defined as the coupling factor, which can either be calculated from a knowledge of the machine parameters or deduced experimentally, as shown below.

Thus, when the effect of cross-coupling is considered, the rotor position estimation error $\Delta \theta$ can be calculated as:

$$
\Delta \theta=\frac{\left(L_{a v g}^{2}-\widehat{L}_{d i f}^{2}\right) p\left(i_{q h}^{e}+\lambda i_{d h}^{e}\right)}{-2 v_{s i g}\left(L_{d i f}+\lambda L_{d q h}\right)}=\hat{k}_{H F}^{\Delta \theta} \cdot\left(i_{q h}^{e}+\lambda i_{d h}^{e}\right)
$$

where $\hat{k}_{H F}^{\Delta \theta}=\frac{\left(L_{\text {avg }}^{2}-\hat{L}_{d i f}^{2}\right) p}{-2 v_{\text {sig }}\left(L_{d i f}+\lambda L_{d q h}\right)}$ is a coefficient which enables the rotor position estimation error to be determined from $\left(i_{q h}{ }^{e}+\lambda i_{d h}{ }^{e}\right)$. In equations (13) and (14), it is noted that the rotor position estimation error $\Delta \theta$ is proportional to $\left(i_{q h}{ }^{e}+\lambda i_{d h}{ }^{e}\right)$. Therefore, by forcing $\left(i_{q h}{ }^{e}+\lambda i_{d h}{ }^{e}\right)$ to be zero, $\Delta \theta$ can be controlled to be zero. Hence, the determination of $\lambda$ is the key to realising the proposed improved sensorless control method.

By definition, the value of the coupling factor $\lambda$ for various combinations of $d$ - and $q$-axis currents can be predicted from the finite element calculated values of $L_{q h}$ and $L_{d q h}$, Fig. 1(b) and Fig. 1(c), as shown in Fig. 2(a). Clearly, the accuracy of $\lambda$, and, consequently, the accuracy of the rotor position estimation, depends on the ratio of $L_{d q h} / L_{q h}$, both $L_{d q h}$ and $L_{q h}$ varying with $d$ - and $q$-axis currents.

The coupling factor $\lambda$ can also be measured directly by driving the BLAC motor by the actual rotor position with an encoder for example. In this way, by injecting the high frequency signal $v_{\text {sig }}$ on the actual $d$-axis, (3) becomes:

$$
\left[\begin{array}{c}
v_{s i g} \\
0
\end{array}\right]=\left[\begin{array}{cc}
L_{d h} & L_{d q h} \\
L_{d q h} & L_{q h}
\end{array}\right] p\left[\begin{array}{c}
i_{d h} \\
i_{q h}
\end{array}\right]
$$

The corresponding high frequency $d$ - and $q$-axis current components are obtained from (15) as: 


$$
\begin{aligned}
& i_{d h}=\frac{v_{s i g}}{p\left(L_{a v g}^{2}-\widehat{L}_{d i f}^{2}\right)} L_{q h} \\
& i_{q h}=-\frac{v_{s i g}}{p\left(L_{a v g}^{2}-\widehat{L}_{d i f}^{2}\right)} L_{d q h}
\end{aligned}
$$

Therefore, it can be seen, from equations (16a) and (16b), that the coupling factor $\lambda$ can be obtained from the measured values of $i_{d h}$ and $i_{q h}$, viz.:

$$
\lambda=\frac{L_{d q h}}{L_{q h}}=-\frac{i_{q h}}{i_{d h}}
$$

The measured coupling factor $\lambda$ for various $d-q$-axis currents are shown in Fig. 2(b). It can be seen that there is an excellent agreement between the finite element predicted and measured coupling factors.

While the value of $\lambda$ to be used in the improved signal injection based sensorless method can be determined by interpolating the data shown in Fig. 2, in order to implement the method on a DSP, the calculation of $\lambda$ is simplified by representing the data in Fig. 2 by a simple function, viz.:

$$
\lambda= \begin{cases}-k_{1} \cdot i_{q}^{e}, & i_{d}^{e} \geq 0 \\ -\left(k_{1}+k_{2} \cdot i_{d}^{e}\right) \cdot i_{q}^{e}, & i_{d}^{e}<0\end{cases}
$$

where $k_{1}$ and $k_{2}$ are coefficients. For the BLAC motor under consideration, $k_{l}=0.05 \mathrm{~A}^{-1}, k_{2}=0.011 \mathrm{~A}^{-2}$ from the finite element calculated value of $\lambda$, Fig. 2(a), and $k_{1}=0.06 \mathrm{~A}^{-1}, k_{2}=0.011 \mathrm{~A}^{-2}$ from the measured values of $\lambda$, Fig. 2(b).

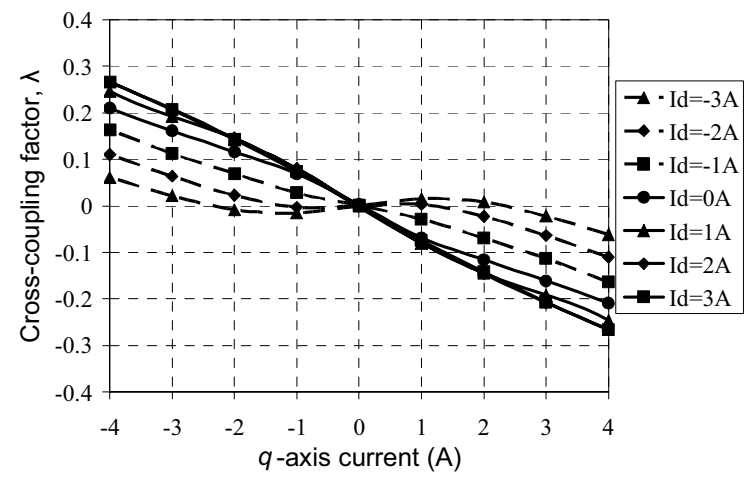

(a) Finite element calculated

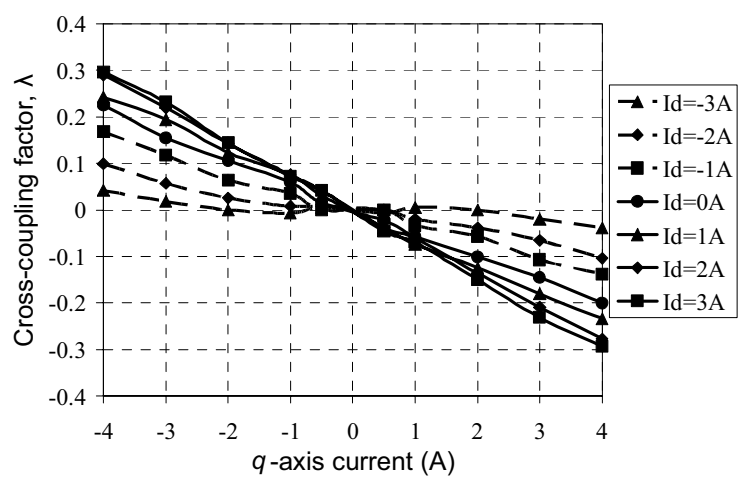

(b) Measured

Fig. 2. Comparison of predicted and measured coupling factor $(\lambda)$.

In practice, multipliers and low-pass filters are used to obtain the high frequency $d$ - and $q$-axis current components, $i_{d h}^{e}$ and $i_{q h}{ }^{e}$, [9], for use in (14) to calculate the error, $\Delta \theta$, in the estimated rotor position. $\Delta \theta$ is then input to a PI regulator to correct the estimated rotor position $\theta_{r}{ }^{e}$ and speed $\omega_{r}{ }^{e}$. Hence, since the cross-coupling is now accounted for in the rotor position estimation, the accuracy is improved significantly.

Clearly, when the cross-coupling is sufficiently small compared with $L_{q h}$, i.e. $L_{d q h} \approx 0$ and, hence, $\lambda \approx 0$, the proposed sensorless control strategy results in $i_{q h}{ }^{e}=0$, and is identical to the conventional signal injection based sensorless method.

\section{Simulated AND Measured Results}

In order to demonstrate the utility of the improved signal injection method, both simulated results and measurements have been obtained for the BLAC motor, whose parameters are given in Table I.

The sensorless controller was implemented on a TMS320C31 DSP, while a 1024 pulse/rev encoder was used to measure the actual rotor position $\theta_{r}$. The A/D sampling and PWM switching frequency were both $5 \mathrm{kHz}$, while the injected sinusoidal signal was $35 \mathrm{~V}, 330 \mathrm{~Hz}$. The control loop cycle was $200 \mu \mathrm{S}$, and the measured coupling factor $\lambda$, shown in Fig. 2(b) and represented by (18), was used, Fig.3, for which a flow-chart is shown in Fig. 4. 


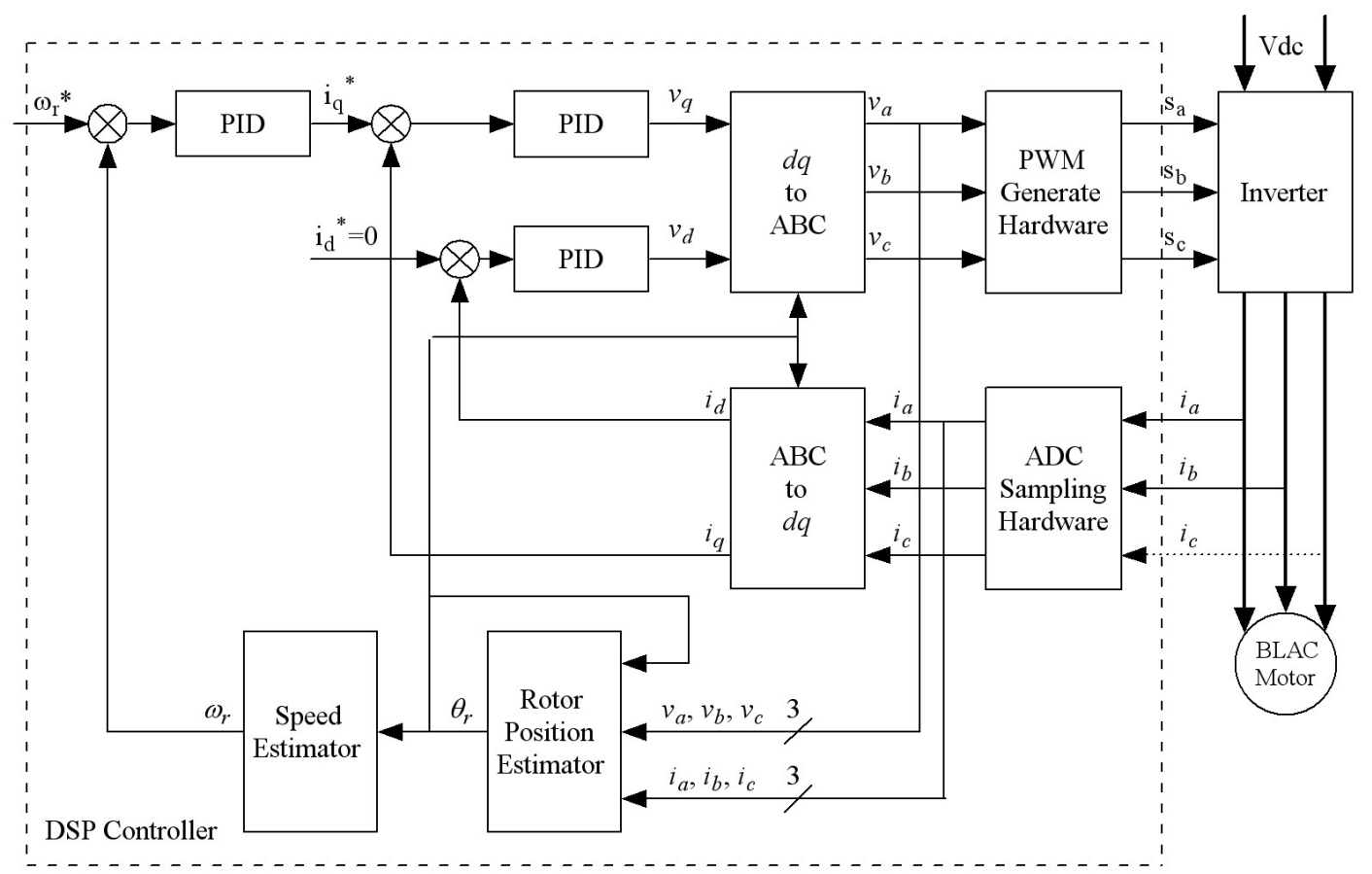

Fig. 3. Sensorless BLAC motor drive system.

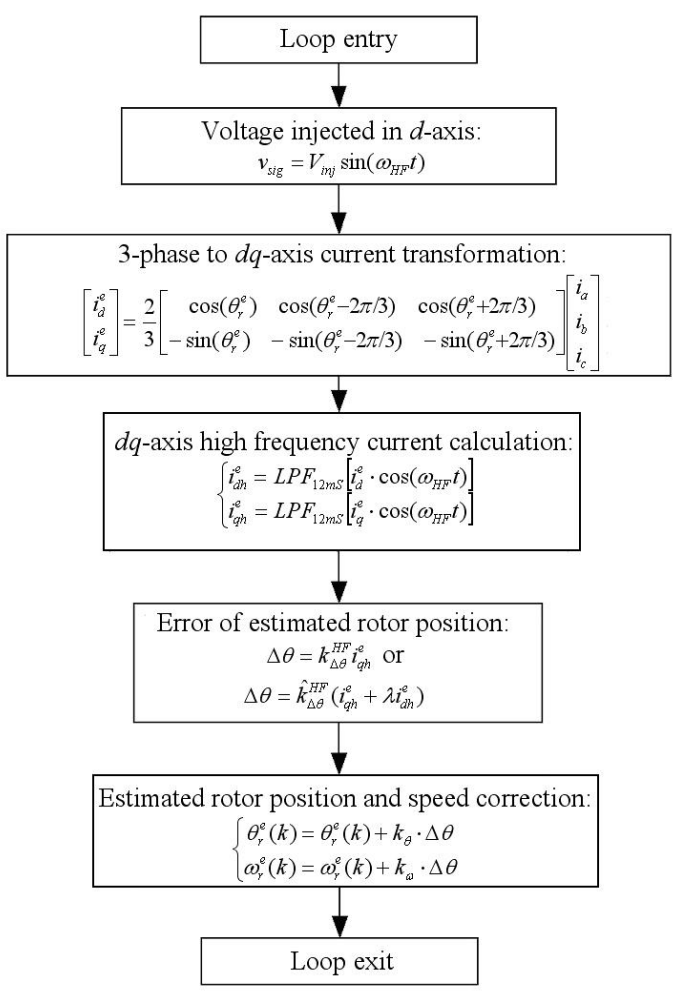

Fig. 4. Flow-chart of signal injection based position estimation.
Fig. 5 shows the estimated and actual rotor position when the demanded rotor speed is changed from $-10 \mathrm{~Hz}$ to $+10 \mathrm{~Hz}$, i.e., $-200 \mathrm{rpm}$ to $200 \mathrm{rpm}$. As will be evident from Fig. 5(a), when the conventional signal injection based sensorless method is employed, good agreement is only achieved when the current is relatively small, the error in the estimated rotor position increasing significantly with the current, e.g. the error is $25^{\circ}$ elec. when $i_{q}=4 \mathrm{~A}$. However, when the improved signal injection method is employed, this error reduces to $5^{\circ}$ elec., Fig. 5(b). This improvement is also confirmed by the simulated results shown in Fig.6.

Fig. 7 shows the measured steady-state error in the estimated rotor position for various $d$ - and $q$-axis currents, $i_{d}{ }^{e}$ and $i_{q}{ }^{e}$, when the estimated rotor position is used for position feedback. With the conventional signal injection method, Fig. 7(a), the error increases as both the absolute value of $i_{q}$ and the positive value of $i_{d}$ are increased, due to increased saturation and the consequent increase in the influence of cross-coupling. For example, the error becomes $45^{\circ}$ elec. at $i_{d}=3 \mathrm{~A}, i_{q}=4 \mathrm{~A}$, the RMS error, from Fig. 7(a), being $21.1^{\circ}$ elec. From Fig. 7(b), when the improved signal injection method is employed, the RMS error is reduced to $2.2^{\circ}$ elec. This improvement is confirmed by the simulated results shown in Fig. 8, for which the corresponding RMS errors in the estimated rotor position are $17.9^{\circ} \mathrm{elec}$. and $1.0^{\circ} \mathrm{elec}$. , respectively. 


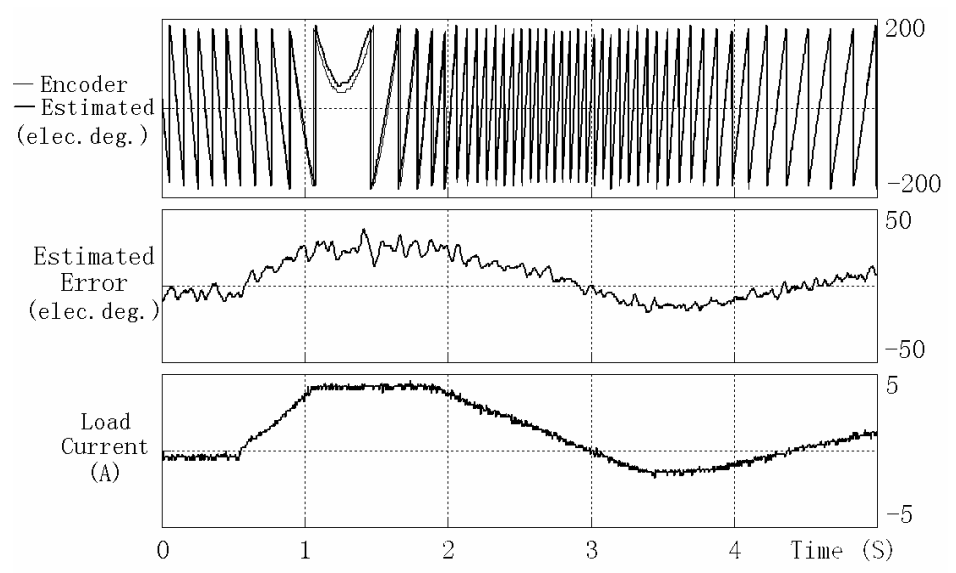

(a) Conventional signal injection method
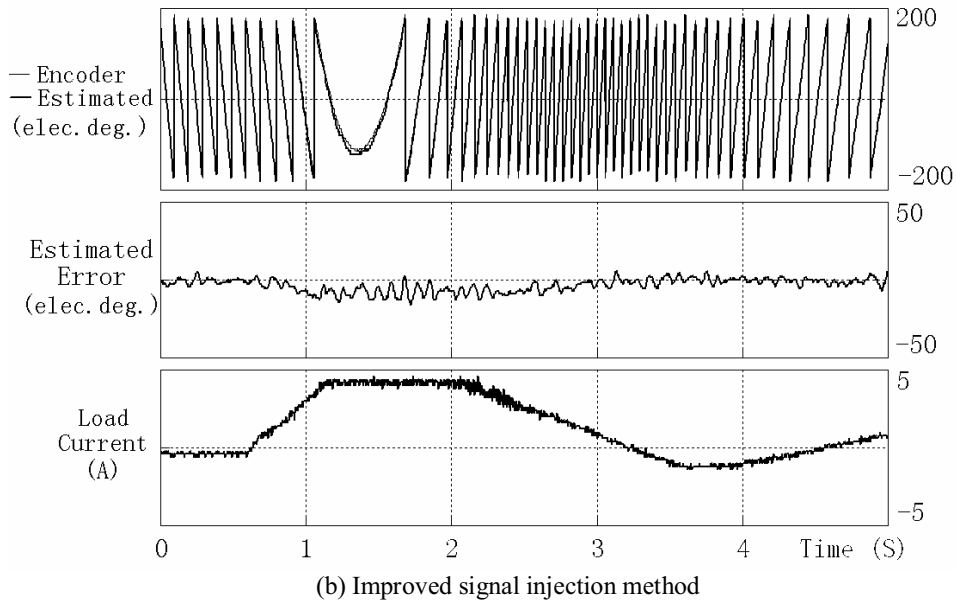

Fig. 5. Measured step speed responses (speed command: $\pm 10 \mathrm{~Hz}$ ).
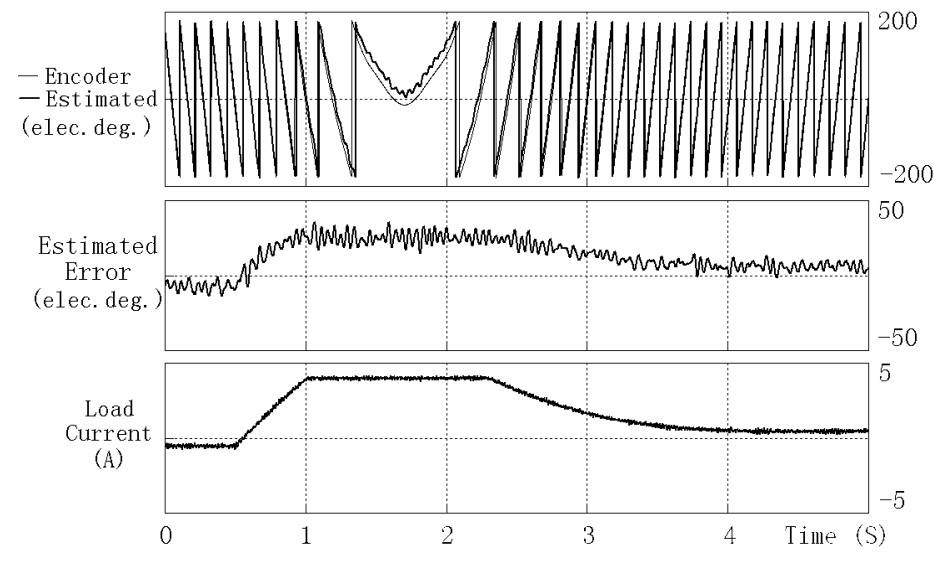

(a) Conventional signal injection method 


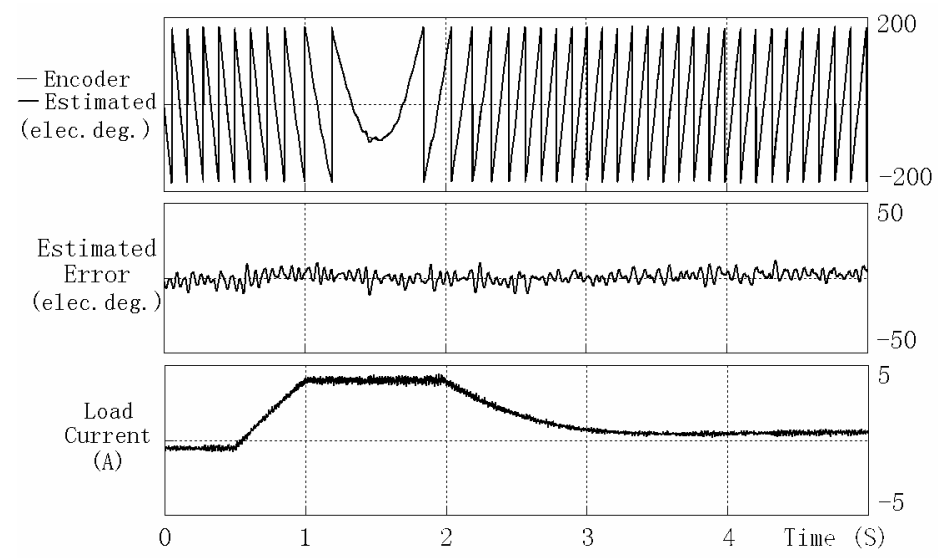

(b) Improved signal injection method

Fig. 6. Simulated step speed responses (speed command: $\pm 10 \mathrm{~Hz}$ ).

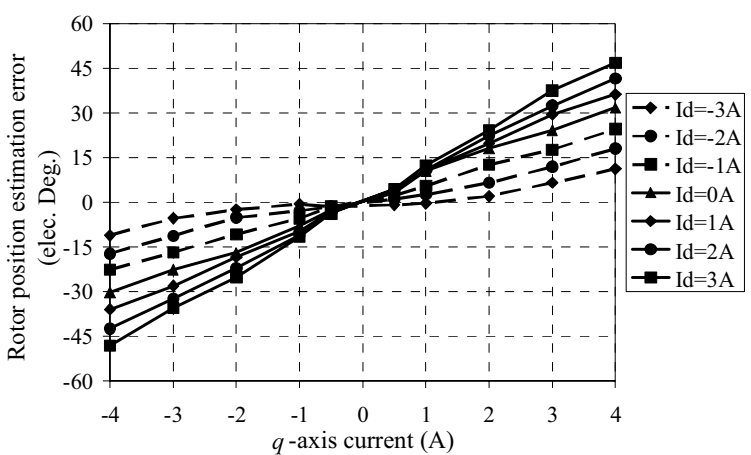

(a) Conventional method, $\operatorname{RMS}\left(\theta_{r}{ }^{e}-\theta_{r}\right)=21.1^{\circ}$

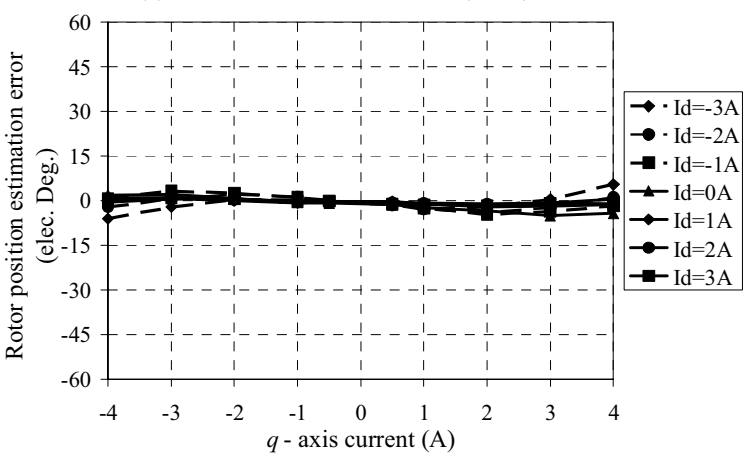

(a) Improved method, $\operatorname{RMS}\left(\theta_{r}{ }^{e}-\theta_{r}\right)=2.2^{\circ}$

Fig. 7. Measured rotor position estimation error.

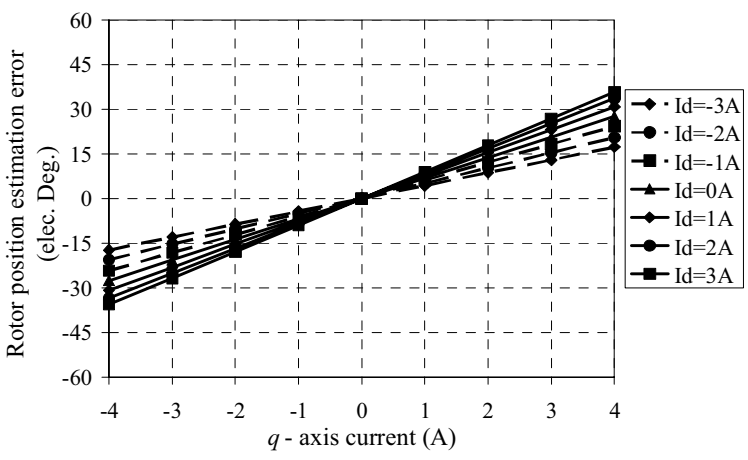

(a) Conventional method, $\operatorname{RMS}\left(\theta_{r}{ }^{e}-\theta_{r}\right)=17.9^{\circ}$

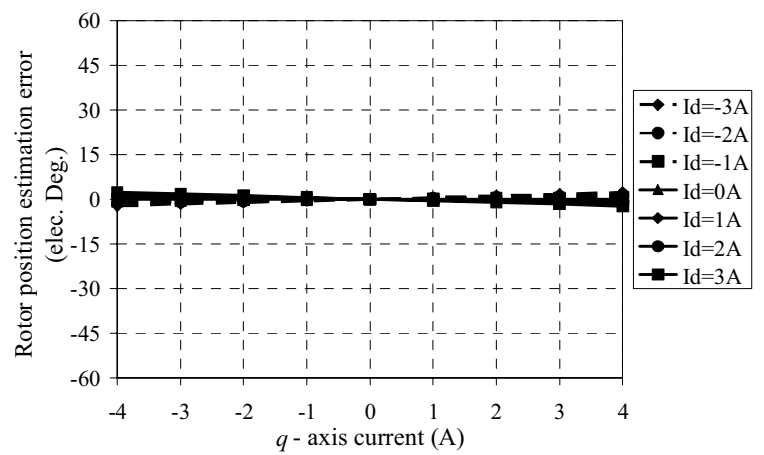

(a) Improved method, $\operatorname{RMS}\left(\theta_{r}{ }^{e}-\theta_{r}\right)=1.0^{\circ}$

Fig. 8. Simulated rotor position estimation error

\section{CONCLUSIONS}

Cross-coupling magnetic saturation between the d- and qaxes of a permanent magnet brushless AC motor can significantly influence the accuracy of rotor position estimation by signal injection based methods. The paper has presented an improved signal injection method which accounts for the crosscoupling effect. The d- and q-axis incremental self-inductances and the incremental mutual-inductance between the d- and qaxes have been calculated by finite element analysis, and a cross-coupling factor determined. An experimental method has also been proposed to determine the cross-coupling factor directly for subsequent use in the proposed sensorless control scheme. Both measurements and simulations show that a significant improvement in the accuracy of the rotor position estimation can be achieved, in both dynamic and steady-state modes of operation, compared with the conventional signal injection sensorless method.

\section{REFERENCES}

[1] K. R. Shouse, and D. G. Taylor, "Sensorless velocity control of permanent-magnet synchronous motors," IEEE Trans. Control System Technology, vol. 6, no. 3, pp. 313-324, 1998.

[2] S. Morimoto, K. Kawamoto, M. Sanada, and Y. Takeda, "Sensorless control strategy for salient-pole PMSM based on extended EMF in rotating reference frame," IEEE Trans. Industry Applications, vol.38, no.4, pp. 1054-1061, 2002.

[3] Z. Chen, M. Tomita, S. Koki, and S. Okuma, "An extended electromotive force model for sensorless control of interior permanent- 
magnet synchronous motors," IEEE Trans. Industrial Electronics, vol.50, no.2, pp. 288-295, 2003.

[4] S. Ogasawara, and H. Akagi, "Implementation and position control performance of a position-sensorless IPM motor drive system based on magnetic saliency," IEEE Trans. Industry Applications, vol.34, no. 4, pp. 806-812, 1998.

[5] M. J. Corley, and R. D. Lorenz, "Rotor position and velocity estimation for a salient-pole permanent magnet synchronous machine at standstill and high speed," IEEE Trans. Industry Applications, vol.34, no. 4, pp. 784-789, 1998.

[6] T. Aihara, A. Toba, T. Yanase, A. Mashimo, and K. Endo, "Sensorless torque control of salient-pole synchronous motor at zero-speed operation," IEEE Trans. Power Electronics, vol. 14, no. 1, pp.202-208, 1999.

[7] J.I. Ha, K. Ide, T. Sawa, and S.K. Sul, "Sensorless rotor position estimation of an interior permanent-magnet motor from initial states", IEEE Trans. Industry Applications, vol. 39, no. 3, pp.761-767, 2003.

[8] H. Kim, K.K. Huh, and R.D. Lorenz, "A novel method for initial rotor position estimation for IPM synchronous machine drives," IEEE Trans. Industry Applications, vol. 40, no. 5, pp. 1369-1378, 2004.

[9] J.H. Jang, S.K. Sul, J.I. Ha, K. Ide, and M. Sawamura, "Sensorless drive of surface-mounted permanent-magnet motor by high-frequency signal injection based on magnetic saliency," IEEE Trans. Industry Applications, vol. 39, no. 4, pp. 1031-1039, 2003.

[10] P. Guglielmi, M. Pastorelli, and A. Vagati, "Cross saturation effects in IPM motors and related impact on zero-speed sensorless control," Conf. Rec. IEEE-IAS Annu. Meeting, vol. 4, pp. 2546-2552, 2005.

[11] N. Bianchi, and S. Bolognani, "Influence of rotor geometry of an interior PM motor on sensorless control feasibility," Conf. Rec. IEEE-IAS Annu. Meeting, vol. 4, pp. 2553-2560, 2005

[12] B. Stumberger, G. Stumberger, D. Dolinar, A. Hamler, and M. Trlep, "Envaluation of saturation and cross-magnetization effects in interior permanent-magnet synchronous motor," IEEE Trans. Industry Applications, vol. 39, no. 5, 2003.

[13] A. E. Fitzgerald, C. Kingsley, Jr., and S. D. Umans, "Electric Machinery", 5th Edition, McGraw-Hill Book, 1992.

[14] Y.S. Chen, Z.Q. Zhu, and D. Howe, "Calculation of d- and q- axis inductances of PM brushless ac machines accounting for skew," IEEE Trans. Magnetics, vol. 41, no. 10, pp. 3940-3942, 2005.

[15] S. Morimoto, M. Sanada, and Y. Takeda, "Inverter-driven synchronous motors for constant power," IEEE Trans. Industry Applications, vol. 2, pp. 18-24, 1996.

[16] J.M. Kim, and S.K. Sul, "Speed control of interior permanent magnet synchronous motor drive for the flux weakening operation," IEEE Trans. Industry Applications, vol. 33, pp. 43-48, 1997.

[17] Z.Q. Zhu, Y. Li, D. Howe, and C.M. Bingham, "Compensation for rotor position estimation error due to cross-coupling magnetic saturation in signal injection based sensorless control of PM brushless AC motors," Proc. Int. Electric Machines and Drives Conference, 3-5 May 2007, Antalya, Turkey, pp.208-213. 